\title{
1965 International conference on Computational Iinguistios
}

$$
\begin{aligned}
& S Y I M A O Q I C \text { A } \\
& \checkmark \dot{A} \mathrm{~S} \text { O I IIG } \\
& I \therefore \because G J A G \equiv S
\end{aligned}
$$

$$
\text { D. } V \text { a } r g a
$$

Computing centre of the Hungarian Acacemy of Sciences

53, Uri u., Bucapest I., Eungary

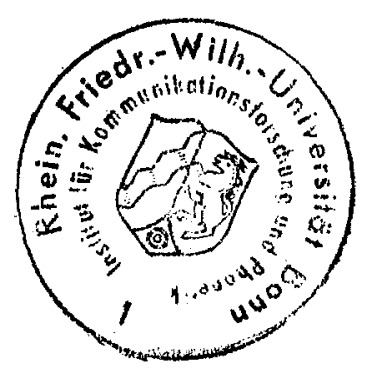




\section{ABSTRACT}

The paper discusses the two main methods rased on the dependency grammars and on P S grammars used in syntactic analysis of natural languages. In the case of highly inflecting languages the IS analysis has the main cisacvantage that they considered syntactically homoceneous caterories the number of rules to be anrlied increases rapicly. The parer rronoses the method of partial decomrosition into morphemes in orcer to increase the efficiency of the rewriting rules, so that the problems of rection and acreement can be solved for highly inflecting languages.

1. Language analysis needs an approach to language different from the generation of the sentences of a Eiven language:

1.1. In the case of aralysis one has to reckon with the fact that because of the restricted accuracy of the woy languare data are cesicrated we can ofter attain our aim/i.e. the estaklishing of the real structure of the scuterce consicered only after the testi:s of several alteriatives, 1.e. it is impossille to solve the raised nroblems irectly, without returns. We have not at our disposal at every etage of the analysis the information that would make a clear-cut cocision possille with resrect to the path to bo follower in the next staces 
of the analysis. This is why it can be said that analysis depends to some extent on the previous history of the analysis. This requirement, however, does not necessarily lead to the reformulation of the rules but may come to the fore in a new way of their application or their order of application [I] of course, it has to be ensured the correctiness 0 i the analysis that the correct structure can be obtained by testing in all. cases..

1.2. If we are interested in the problem not only from the side of theory iut also that of its practical applicability, then we have to ensure the optimalization of the way the correct structure is revealed. The optimalization of analysis is related - in many respects - to the requirement of simplicity in language theory. Of course the method to be applied is not independent of the typological properties of the language under consideration, and this applies, above all, to the optimalization.

1.3. If we aim at the analysis of natural languages our main requirement may be much less stringent than the requirement of generative grammars. Generative grammars, quite reasonably, consicer as a 
principal requirement that any grammar should generate alI sentences of a given Ianguage and only these. An analogous stipulation is not necessary in the case of analysis since we may assume that we want to analyze only impeccable sentences. In the cese of artificial languages - for jastance. in the case of programing languages - the stitimion is quite different: it is a basic requirement that the analyzator should be able to distinguish the syntactically impeccable strings from the incorrect ones, i.e. that he could disclose the syntactic faults./

Now the question is that what kind of methods or which combination of methods may lead to the recognition of the structure or structures of any syntactically impeccable sentence, within optimal time and with especial regard to highly inflecting languages.

2. With respect to the non-inflecting or only weakly inflecting languages there is a useful method for aralysis, namely, the reversed application of the so-called rewriting rules. Besides its 
simplicity, this nethod offers quite a few advantages, finstly, it is based on the ....thematically well-formalized phrase structure gramars, secondly, from a linguistic point of view, it is related to the IC gramnar that has been elaborated for the analysis of natural languages.

In the case of inflectional languages, however, the application of such rules mects with a difficulty which is due to the fact that the application of such rewriting rules means the processing of symbols assigned to the categories of syntactically homogeneous elements. The number of the categories consisting of such syntactically homogeneous elements is very high in these languages and each adcitional category increases the number of the rewriting rules by so nany rules as there are cifferent structures in which the category in question may occur. The number of rules would amount, for instance, in Russian to about 30-40 thousand, which diminishes the applicability of the system considerably.

The excessive increase of the categories is mostly cue to the fact that the classifications accorcing 
to the differeat points of view may oocur inceperdently of each other. If $\underline{m}$ difierent basic caterories were needed accorcing to one aspect of classification and $\underline{\text { a }}$ ilferent categories according to another aspect then, taking into account both aspects, $\underline{\underline{-}} \underline{n}$ different besic categories vould de called for. If, for instace, the classification of substantives according to rection needed seven basic categories, the classification according to the cases 6 basic categories, and the classification according to the numbers 2 different categories then - instead of a single substantival /N/ category - 7.6.2 = 84 categories would be necessary. It is easy to see that should we take into consiceration the differences between male and female, animate and inanimate, let alone the semantic categories, then we would obtain a completely unnanagable apparatus.

3. Dependenoy grammars have been elaboratec mainly to circumvent the cifficulties raised by inflectional languages. It is interesting to note in passing that in the soviet Union this concention prevails even today in the groups engaged in ma- 
chine translation. According to dependency grammar we have to consicer the category of the distinguishad wor form as a representative of a complex catecory in each case a rewriting rule is appliec. In this way the concretness of the categories is maintained. Iastly the predicate represents the whole sentence, standing as it coes at the top of the tree diagram.

At first glance a deperdency grammar seems to exhibit quite a few advantages from the point of view of highly inflecting languages. This advantages may be summarized as follows.

(i) It traces back the relations within the sentence to the relations between concrete word forms. In this way the estatishment of the sentence structure is traceable back to the establishment of the relations between concrete words, i.e. to the examination of micro-structures.

(ii) In the case of highly inflecting languages where the relations between words come to the fore through their outer form, namely through the form of agreement and rection, the information obtained in this 
way may be used immediately for finoing out the sentence structure.

(iii) On the basis of the direct relations between words the analysis may start at any point: at the top of the tree diagram on at the bottom or in the order given by the words of the sentence.

(iv) No difficulty in principle is encountered in a dependency grammar analysis in the uniform handling of continuous and discontinuous structures. /These structures are rather frequent in highly inflecting languages, cue to the fact that they have more effective means at their disposal than word order for expressing relations between woròs./

In spite of these advantages depencenoy grammars have not solved the problems definitively as it has turned out that these advantages are only of a rather restricted character.

AO (i). It may happen that the examination of the relation between two wor os does not provide enough information for further analysis. The statement of complementary concitions is rather difficult in 
these cases and can be cone most cases only by an ad hoc adjusment.

Ad (iii). Although it is possible to begin the analysis at the top of the dependency tree, such an analysis cemancs either a rather laborious testing process or the storing of a grat amount of information. / It is illuminating from this point of view to follow the development of predictive analyses beginning with the original conception of Ida Rhodes up to the variant elaborated by Kuno-Oettinger-Plath. Accoring to Rhodes the analysis is to be carried out on the basis of depencercy grammar, beginning at the top of the dependency tree. The new version of cependency gramar is based thoroughly on the conception of IC grammars. As is known, the mair defect of the earlier version was caused by the fact that when longer sentences were to be analyzed the precictions to be stared increased in an excessive way./

Ad (iv). In principle it woulc be possible to anaIyze all possible cases of the discontinuous structures but such a full analysis seems to be unattainable in the forseeable future. / Kulagina's main 
endavour is aimed at excluoing on the basis of a preliminary analysis those constructions that cannot be further expected and maning possible this analysis equal to the rull analysis[2]/. In practice the analysis is always carried out on the bäsis of some simplifying conditions or hypotheses concerning chiefly the decomposition of sentences or the relations of some structures /projectivity/.

4. Iifferent methocs have been proposed to circumvent the difficulties raised by the IC grammar anaIysis. Chomshy tackles these proposals/proposals of Harris, Matthews, StockweIl, Anderson, Schachter, Farman and others/ in his paper submitted to the Nagdeburg conference; he concludes, the problem of remedying this defect in $P S G$ is clearly very much open, and ceserves much further study" [3]. With respect to fussian it is Plath who has recently elaborated an ingenious indexing and index-transmission system which sets out to ensure the manysiced applicakility of the rules and the transmission of the information from one symbol to another. Chomsky points to the fact that the incexing of 
categorier and the introduction of complex symbols means essentially the application of a special type of transformational gramar. Tncoubtedly, the pure methods have not yielded the expected results in the analysis of natural languages. Chomsky himself suggests a compromise with respect to similar difficulties that arise in generative grammars. Practically it goes about a new dimension, neglected so far, nemely about the paradigmatic lavel. Chomshy posed the alternative straightforwardy : either one should accept the decomposition into morphemes or opt for the paracigms. He himself pronounced in favour of the paradigmatic conception.

Chomshy has been led to this decision by the complexity of the morphemes. However, it should be added that quite different questions arise in the case of agglutinative languages where the inflectional morphemes generally serve to express a single gramatical function. So, for instance, in Hungarian házałnak =

$$
\begin{aligned}
&= \text { ház }+a k+\text { nak } \\
& \text { house }+P I+D a t
\end{aligned}
$$

If we take account of this structure of words the decomposition into morphemes seems more justified. 
Taking into consiceration the aspects of the syntactic analysis an intermediary solution offers itself: with the aio of common rewiting rules/without increasing their number essentially/a considerable part of the syntactic relations may be detected if we decompose the sentence - but only partially - into morphemes, i.e. If we separate the case category from the basic category. This means that weemay use the same symbols for the designation of cases of substantives, adjectives, pronouns etc. and it is necessary to decompose the corresponding categories. On the other hand, the case category is handed separately, the role of which is a syntactic one in the first place. last but not least it facilitates the separation of case and gencer - number which is important in the processing of relative pronouns.

A sinilar situation can also be produced artificially in the case of the machine translation of nonagglutinative languages. As in machine translation the morchological analysis precedes the syntactic one, in practice there are no difficulties to transform the occuring word forms on the basis of the morphological analysis carried out 
previously in such a way that the grammatical information becomes explicit and so the word forms are rendered "agglutinative".

To find out the rection we have usually to take into consiceration the following factors:

a./ the category of the construing word stem;

b./ the case ending of the construed word;

c./ the category of the construed word stem.

It is, however, unnecessary to consider the case ending of the construing word. D.g.

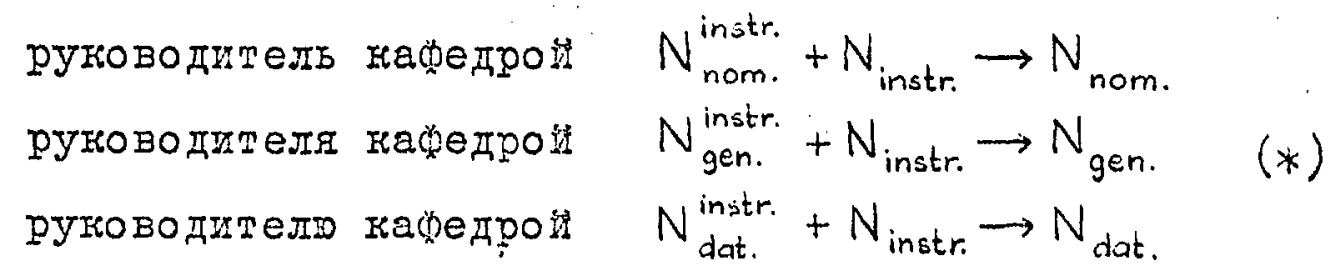
By separating the case ending and by placing it before the word have instead of $(*)$ a single rule:

$$
N^{\text {instr. }}+\text { instr. }+N \rightarrow N
$$

The rection can be examined by means of simple context-restricted phrase structure rules:

$$
\begin{aligned}
& A+\alpha+N \rightarrow N / \alpha- \\
& A+\delta+N \rightarrow N / \delta-\quad \text { etc. }
\end{aligned}
$$

The decomposition into morphemes can also be used with respect to the participles and the infinitive. consequently the problems connected with the rection 
of participle as verbal derivate may be handled separately from the problems connected with the participles as secondary parts of speech being embedded in the structure of the sentence.

5. The advantages of dependency grammars derived from the fact that they could draw conclusions with respect to the type of the relations taking no account of the arrangement of the words in the structure of the sentence only by examining separate concrete words. With respect to some local units the same holds in the case of an IC analysis as well. Such local examinations can be used as input information to further analysis, and on the other hand, they may effect the reduction of the number of the possibilities to be considered.

1. A typical local problem is represented by the morphological analysis which means/in common parlance/ the determination of the grammatical properties of separate words.

2. As local problem may be considered, for instance, the agreement of the substantive with the immediately preceding adjective/s and/or preposition in Russian. /The risk to make a mistake 
is minimal, although it is not entirely unlirely because of the adjectives that may be used as substantives too:

В столовой девуште дали обед.

Such preliminary examination of compatibility is of great importance in MT because hereby the number of case homonymies may be reduced essentially.

3. Ne place the examination of the possibilities of extension or of the realization of these possibilities among the local problems, at least insofar as it provides preliminary information for the analysis. The number of these possibilities is limited anc is characteristic of the language uncer consideration. First, in what direction and second, what kind of gramatical and lexical methods may be used for the extension, the continuation of a word or structure. It is highly revealing to examine how a given structure can be extented starting froma single sentence kernel/i.e. not from several full sentences/. So, for Instance, in Inglish:

Sometimes a decision to compute is followed by a process of selecting the particular kind of computing machine best suited for the given problem. 
or

The designer should be careful in choosing cirouit designs that he not build in adiitional difficulties with a choice of a particular circuit in an attempt to eliminate other difficulties.

The same grammatical relations would be expressed in Hungarian or in Russian in entirely different ways. /We would have full clauses instead of participles in Hungarian, in Russian the participles would be replaced by substantives derived from verbs/.

4. Semantic information may also be used for the reduction of the possibilities in the case of a partial analysis of ambiguous structures. In case of no ambiguity it makes no sense to use semantic information if we assume that the input sentences are impeccable not only gramatically but also semantically, ef.1.2/. Notice that the constructional homonymy extending over the whole sentence is rather unusual, we have, however, frequent cases of ambiguous structures within sentences. So, for instance, in kussian the string "вследствие друпих законов сохраненил, а такте особенностен взандодейcmsing qастип" 
may have 7 different bracketings, i.e. 7 different structures. If there are several syntactically ambiguous structures in the sentence then it would be unnecessary to carry out a new. syntactic analysis for each of them: if we can localize the ambiguous structure the production of all possible sentence structures is merely a matter of combination.

The mentioned local problems need not be: incorporated into the main program, i.e. the proper syntactic analysis. A considerable part of them may be carried out either previously or simultaneously with the morphological analysis, while other problems may be solved as subsidiary operations, in each case separately, when some rules are applied, if necessary.

6. The crucial point of the syntactic analysis of the whole sentence/i.o. not of the form of the rules, but of the strategy of their application/ is the problem where to begin the analysis, i.e. at which word of the sentence [4]. Iees says with respect to the order in which the transformational rules must be applied, that one has to begin with 
the constituent sentence that is embedded deepest and that further trensformations can only be applied to matrix sentences previously "satisfiec". This holds - mutatis mutandis - with respect to the simplest structures, word groups as well. /Namely, assuming that we begin with the analysis of the given string to be examined,i.e.from the bottom of the tree. The other possibility is to begin from the top of $\therefore$ presupposed tree diagram, i.e. with the hierarchy of the given system of rules. This path has, been followed in predictive analysis/. A basic problem is the determination of the structure that is embedded deepest in some other structures. If we have succeeded in determining this structure then we could obtain the analysis of rather complicated sentences by a stepwise processing of the embedied structures in a rather simple way. Naturally, if it is wanted that an exroneous step should not destroy the whole analysis the different possibilities must be remembered by the algorithm. A suitable algorithm worked out by Bálint pömölki [5] could be used with only slight alterations for the analysis meeting the above requirement.

We can considerably diminish the number of the unne- 
cessary blind alleys by taking into consideration the type of the language under consideration. As to Russian, for instance, the right recursive rewriting rules prevail. There is a right recursivity, for instance, in the case of substantival complements connected with substantives, adjectives, participles or the participial constructions embedded in each other etc. According to Yngve's terminology we can say that a considerable part of the Russian structures are of the progressive type.As a consequence, the tree diagram of the sentence is in most cases characterized by right-branching /or at least this holds for some subtrees of most structuresh In this case, however, we arrive at the deepest part of the right-branching tree in the simplest way if we begin the analysis at the end of the sentence. To put it differently, if we consider the sentence structure given by a bracket expression then in the case of progressive languages we have often a case of the brackets accumulating at the end but not at the beginning of the sentence. To take a simple example, we have in Russian such sentences as

(Вн (знаете (много (теорем (о тределах))))) If we began the analysis at the beginning of the sentence, we should have to try connecting quite a 
few words and structures that are in fact separated by brackets, that is that are not connected with each other. If we start, however, at the enc of the. sentence and embed the obtained symbol corresponding to the structure discovered till that moment into subsequent structures we can arrive at the correct, analysis of the whole string more quickly and with less effort. 
[1] Cf. Abraham, S., Some questions of phrase structure Grammans, Comotationa? İnguistics IV. Fowthoonine/

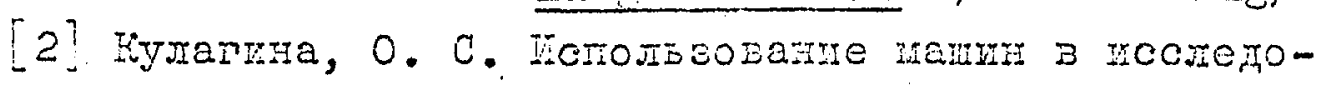

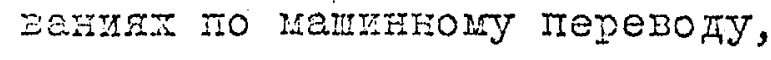

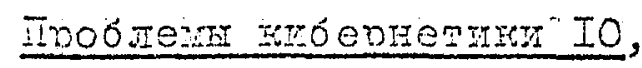
po. $2 C 5-2 I B$

Вакуловскал, Г. В., Кулагина, О. С., об онном crocose amajrisa rercia, inpoú-

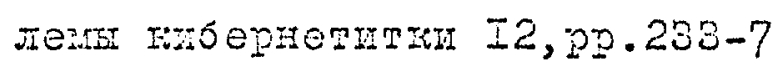

[3] Chomsiry, I., Categories and Relations in Syntacted wheory, mimeographed, DN 7, 1964

[4] Varga,D., Ingrve's Hypothesis and Some Problems of the Mechanical Analysis, Oorputational Iinguistics III, pp.47-74

[5] DömöIki,B., An Algorithm for Syntactic AnaIysis, Computational Iinguistics III, $p p \cdot 29-46$ 